\title{
Developing Skills and Measuring Competences Through Simulations in Corporate Environment
}

\author{
Aron Solecki \\ Apertus Ltd., Budapest, Hungary \\ Email address: \\ soleckia@gmail.com \\ To cite this article: \\ Aron Solecki. Developing Skills and Measuring Competences Through Simulations in Corporate Environment. Science Journal of \\ Education. Vol. 7, No. 4, 2019, pp. 87-90. doi: 10.11648/j.sjedu.20190704.12
}

Received: April 30, 2019; Accepted: June 19, 2019; Published: September 5, 2019

\begin{abstract}
If created along the principles of engagement, relevance and measurability, learning games offer appealing benefits both for managers (project sponsors) and employees (end-users). Yet widespread use of such serious games at forprofit organisations may be set back by financial barriers. The article focuses on how to create simulations cost-effectively and at a good quality level at the same time. The key is to advance in small, consecutive steps, creating short, self-contained stories with a limited number of characters in a relatively simple, unchanged environment. On a simple and steady platform of a few strong-featured heroes, together with their business and human relations, a complex world of intricate narratives may be built up as new topics are treated. As developers we do not need to make big promises about the numbers of learning goals and skills to improve. We just start by stating that we can set up a modular system of simulations in a relatively inexpensive way. If we do it right, there will always be enough interest (and money) to expand the horizon. Nevertheless, it is still true that we need a considerable investment of trust and financial resources at the beginning, just to be able to introduce the characters and setting to the audience just as well as to create the appropriate software background.
\end{abstract}

Keywords: E-learning, Skills Development, Gamification, Game-Based Learning, Simulation, Short Sim

\section{Introduction}

The Homo Ludens gamifies, and so do an increasing number of organisations that strive to gain and retain top quality workforce. We want to re-create our workplaces as engaging as possible in order to get ready for the way the upcoming generations will learn, cooperate, or seek for information. To achieve this, we rewrite our onboarding materials as well as our standard and individual courses. Yet this does not mean we will have infinite resources to refine our curricula. We have to find the most costeffective (and other resource-effective) methods to impress and develop people. So far, simulations have been thought to be adequate and fashionable tools for "impression" (gamification) - in exchange of a great financial effort. Let us see, how they can be made cheaper without looking to be cheap.

\section{Diverging Interests of Employees and Employer Concerning L\&D}

In a corporate environment, in the very moment gamification comes to sight, the need for measuring outcomes emerges too. Management not only want to be aware of all input and output variables but also master them, fine-tune the requirements and key performance indicators.

The more breath-taking a learning content is, the harder it is to retain its relevance and measurability. [1] A professional task or situation becomes a game when its meaning goes beyond the everyday level, that is, it becomes a metaphor to the user through gaining particular importance, giving pleasure or energizing the user in any other way. Metaphors, however, are absolutely elusive when measurability comes to question. The beauty of metaphors may not be qualified or quantified. It depends, you know... In the case of a gamified product, the triangle of engagement, relevance and measurability is quite twisted, and it is not at all simple to reconcile these conflicting factors. 


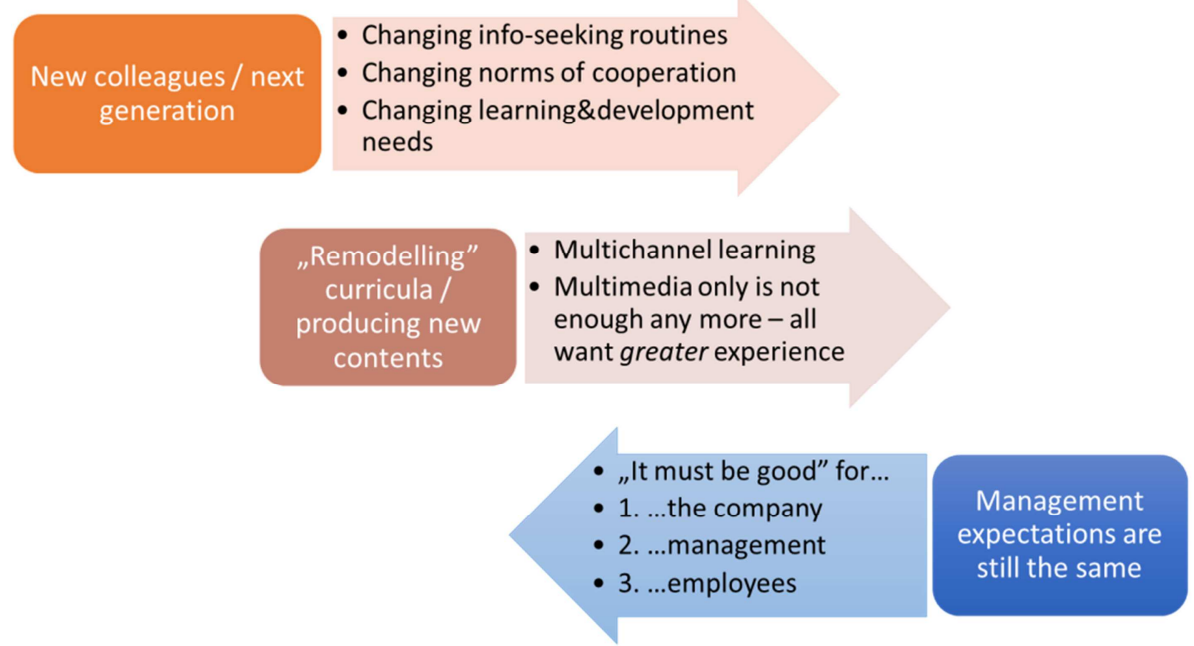

Figure 1. Management expectations often set limits to enhanced learning experience.

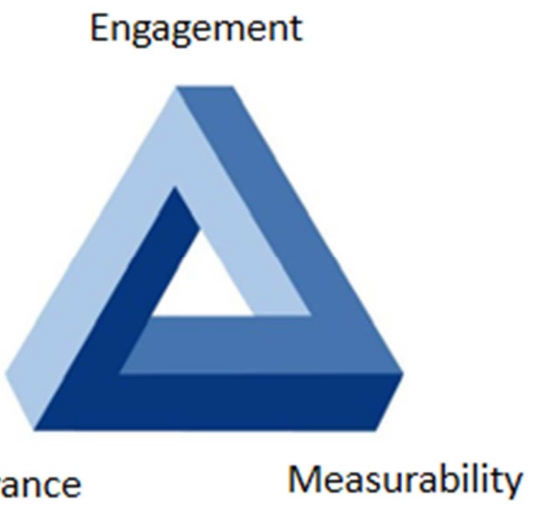

Figure 2. The twisted triangle of engagement, relevance and measurability.

Engagement:

a) The target group should feel the urge to complete the course.

b) It must not be over-didactic.

Relevance:

a) The content should target to reach definite learning goals.

b) It must be scalable / refineable.

Measurability:

a) The structure has to contain basic measurement points - and be able to host even more in the future.

b) It must be aligned with corporate strategic goals to prove that it is worth the investment.

\section{Money Would Help - If We Had Enough}

As widely experienced, money helps to find the balance among the above three factors, as it does in many other fields of corporate functioning. Since time is money too, let us expand the above illustration into the third dimension, turning it into a tetrahedron by adding another vertex (namely, price) to it.

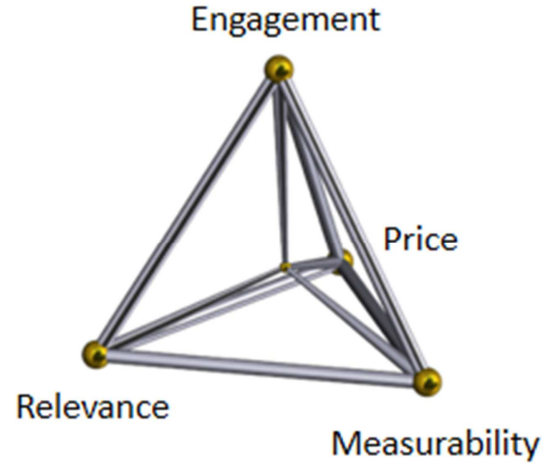

Figure 3. As soon as the vertex of Price appears, the formerly unreal triangle becomes a useable tetrahedron.

This implies that we get a "good" gamified e-content if we do not overcomplicate it, or if we (our customer, to be more precise) spend (s) a lot of money on it. As we all know, an impressive-looking and eye-catchingly functioning curriculum requires lots of development hours. Moreover, when it comes to meeting deadlines, resolving the time pressure will blow up the budget.

This sounds like sad news about complex simulations, or to be more precise, to situational contents which, based on decisions between confronting interests, help gain and synthetize new information, develop skills and aim to measure the change. [2] (In this regard, simple software mock-ups are not real simulations because they lack compound tasks, weighing alternatives and information from several different sources - software mock-ups at a basic level are drills, and not challenges.)

Users immerse in simulations, and our aim is to benefit from that immersion, because their skills and routines improve which they will use to raise profits. As Clark Aldrich put it, "role of short sims is to develop competence and conviction." [3] When we succeed in leveraging the aspect of relevance, engagement and measurability during the development phase, our simulation game will be appealing for both users and their 
employers, and thus, it will be "destined" to be a hit. Still it is not easy to avoid cost overrun. And when the budget is too high, the customer will call off the development. By looking around for "cool" current simulation contents, we easily find products targeting wide audiences without any limitations on language, industry or professional experience.

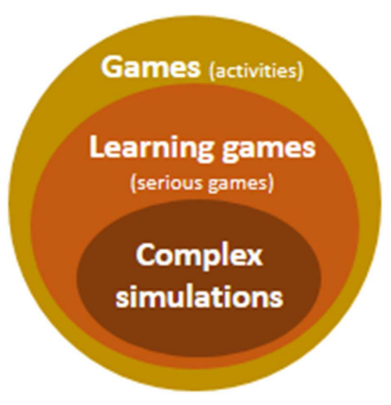

Figure 4. Games in e-learning.

\section{The Way to Stay Cost-Effective}

If we still want to develop a unique product for precisely defined audiences in a special field of interest, our content needs to remain relevant, engaging and measurable without presenting an extremely high budget - that is, staying at a comparative cost level to any other multimedia e-learning contents. The easiest way to reach this is not to dream too big. We need to find the minimal length and complexity which is enough to become both engaging and valued, and able to distinct changes in knowledge, skill, or attitude. Thus, "applied simulation" is always a short sim or micro-simulation.

Ensuring cost-effectiveness is not at all obvious during the development process of complex applied simulations. Whereas we can use more or less of any ingredients of "classic" elearning (or even omit some of them), simulations, above hard content and illustrative materials, always have to have enough "spice" to be attractive enough to redo and discover various layers of contents. By spice we mean alternative endings, Easter eggs, commentaries, and so on. [4]

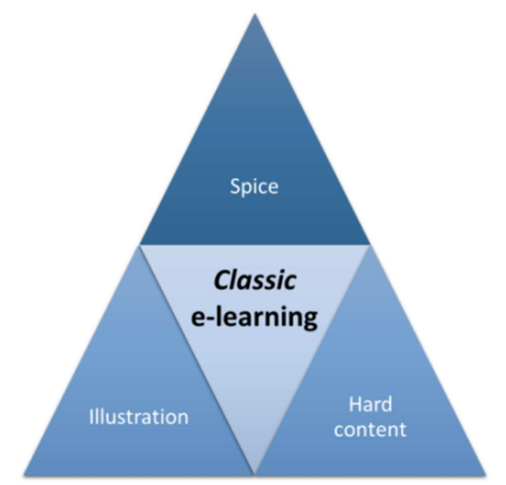

Figure 5. Geometrical illustration, again: basic components of e-learning contents.

We can control the number and cost of the ingredients relying on the following precautions:

a) Short introductions, less detail to background, few actors and actresses, limited number of outer locations and props. b) Simple and trouble proof logic, few variables to count and follow.

c) Avoiding unique software development tools (sticking to standards and predefined templates), keeping everything to minimum under the hood.

d) Expecting and building on the other (following) elements of the system: relying on content outside of simulations, expanding and elaborating themes in sequels (another sim - another budget!). Blended learning or additional presence learning / training sessions may also enrich the effect of the sims. [5]

Considering the effects of these principles on the main attributes of simulations, when it comes to relevance, we shall use not more than 5-6 characters and treat one single problem with 1-2 key variables at a time. We start "in medias res", that is, straight to the point. This is not a drama or an epic fantasy but rather a situational comedy. Furthermore, there is an additional benefit: with such a puritan setting, we also please those who favour microlearning. [6]

The script is strictly defined by the aspect of measurability, focusing on the difference between the basic (input) and targeted knowledge, level of skill or competence. [7] This entails that our writers are more like screenwriters than original authors. [8]

When it comes to resources (the pricey development phase), we must not divert from a given technical set. We use the same engine, and consider any additions through the optic of reusability. "Engine" here is a collective term which may refer to year-long developed special frameworks to webbased solutions. Choosing on-line tools does not necessarily mean poor user experience. The available machinery to develop nonlinear stories ranks from the simplest, cheapest and quickest [9] through more elaborate and visualized [10] to LMS-integrated platforms. [11]

We always keep in mind that there is no standalone (micro-) simulation or short sim. Engagement is ensured by unfolding an elaborate story and interesting characters through sequels and prequels, and we put large emphasis on additional contents. [12] A micro-simulation is never intended to be a Fabergé egg, a unique, self-contained and all-embracing entity. Creating a complete world takes time and requires new assignments, so it is being built out by lots of micro-simulations, together with the other elements of our education programs, all presenting opportunities to discovery, that is, pull type knowledge acquisition. [13]

As the imaginary world of main characters and their basic relations expands, there will be time and place to shoot additional videos, creating social media profiles [14], webpages, thematic spin-offs, all of which having their own costs. [15] The larger number the sims have the better this additions will pay off - and, of course, the less unit price they will have, which really does sound good for customers who tend to order only the minimum and focus on hard content.

If we do not succeed in the long run, we will not make a great impact. When a complex world of characters, situations and challenges emerges, that will be the proof of being able to successfully develop micro-sims (short sims) with appropriate 
sense of balance between business and end user orientation. Then, the development team of content creators, visual artists and software developers may even expect a commission of a large-scale interactive film or one-and-only programme, offering enough time and space for twists, turns and crowd scenes. The success will then be guaranteed, because by then, a zealous audience will already be formed, who are eager to actively take part in the interpretation of the content as well as in providing new perspectives and needs of further elaboration.

\section{Rolling Out (to the Infinite)}

Omne initium difficile est - all beginnings are hard. Interestingly enough, this does not only refer to the primary efforts of finding out about the setting, the characters and their relations, together with fighting out the initial production budget. As developers, we have to get used to - and even promote - the fact that we cannot present all aspects of learning at the beginning. That is, we cannot tell the exact number of skills to be improved, learning points to be treated, and variables to be measured even if asked to give estimates (or rather exact figures) for certain time frames and diverse budget levels. It is not scientific nor businesslike to say that "we will work that out later, together" - still it is the only way to stay straightforward during long term project planning. It would be worth to do some research into the way management and end-user reception shapes the themes, goals, and style of forthcoming microsimulations. If we value engagement high enough, then we must take feedbacks seriously and continuously re-shape our plans while scripting the new sequels.

\section{Conclusion}

The business model of developing micro-sims requires moderate handling of creativity and technology - yet doing so in consequent, steadfast steps. "Applied simulations" for corporate customers may be adequately varied and realizable for a reasonable price at a time. Yet for their success it is inevitable to produce them in series and together with additional contents and/or training sessions.

The principles of engagement, relevance and measurability do not only define the mode of action of learning games but also the way we should approach simulation development straight from the beginning. Our intellectual product - the simulated world, its heroes and their basic motives - must be interesting enough to raise expectations (both on employee and employer sides) for forthcoming episodes of their stories, and to prove that they can be the most adaptive and versatile means of people development in the corporate L\&D toolset.

\section{References}

[1] Before dreaming on, we should stop and ask a few fundamental questions about learning objectives, learners, and resources, as Jenny Saucerman does: http://twist.elearningguild.net/2018/02/when-simulationswork-jenny-saucerman/
[2] Basic categorisation taken from here: http://www.theknowledgeguru.com/games-vs-simulationschoosing-right-approach/

[3] Clark Aldrich's manifesto on Short Sims is available here: https://docs.wixstatic.com/ugd/9650eb_3597a7fd99694f2d95a 8238126c49acc.pdf?dn=Short+Sims+by+Clark+Aldrich.pdf or through a shorter link: https://www.shortsims.com/podcast, 2 January 2019 episode, titled Short Sims the Cover Story on the Industry's Flagship Publication

[4] We cannot do without „spice” in simulations. By definition, simulations are about alternatives. In simulations, users learn by doing, and they have to face the consequences of their decisions immediately.

https://www.elearningguild.com/pdf/2/091702des-h.pdf

[5] E-learners should talk to each other about what they have experienced. Personal contact may not be substituted even by the best-quality simulated world. Other advantages of blended courses are listed here:

https://www.teachthought.com/technology/the-benefits-ofblended-learning/

[6] You may find a short definition and actual trends of microlearning here:

https://elearningindustry.com/microlearning-trends-in-2019adopt

[7] For those who want to go further into details of what and how to measure in e-learning, I suggest the following article to start with: https://blog.commlabindia.com/elearning-design/coursetracking-to-improve-elearning-effectiveness

[8] Why is it important to use the screenwriter approach? Elearning Brothers tell us with a picturesque example: $\mathrm{https}$ ://elearningbrothers.com/blog/importance-script-writingvideo-presentations/

[9] Twine is free and open-source: http://twinery.org/

[10] Add-on free toolkits are, for example: https://www.ispringsolutions.com/; https://www.branchtrack.com/

[11] More about the Simformer platform available here: https://simformer.com/

[12] By additional contents, the importance of "something to take away" must be stressed, like downloadable materials: https://elearningindustry.com/tips-use-downloadableelearning-content

[13] Aptly defined, "in a push strategy, individuals actively encode their knowledge to make it available for others. In a pull strategy, team members seek out experts to request knowledge sharing, so you only transfer knowledge on an as-needed basis." Source: https://www.smartsheet.com/knowledgemanagement-101

[14] For advantages and rules of use of social media in e-learning courses, see Marina Arshavskiy's article: https://elearningindustry.com/improve-formal-learning-withsocial-media-social-media-elearning

[15] ...yet all pointing toward personalised learning, expanding and deepening the learning cycle. https://spinofflearning.com/2018/07/31/personalised-learningand-the-sigma-problem/\#more-1074 